\title{
Pelatihuan Aplikasi Mendeley untuk Taruna-Taruni Prodi D III Teknologi Elektronika Perkeretaapian untuk Persiapan Pembuatan Proposal Tugas Akhir
}

\author{
Mendeley Application Coach for Cadets-Taruni Prodi D III Railway Electronics \\ Technology for Preparation of Final Task Proposal \\ Dhina Setyo Oktaria \\ Prodi D III Teknologi Elektronika Perkeretaapian, Politeknik Perkeretaapian Indonesia Madiun \\ e-mail: dhina@ppi.ac.id
}

\begin{abstract}
Abstrak
Pengabdian masyarakat ini bertujuan untuk dapat meningkatkan pemahaman dan kemampuan taruna-taruni program studi D III Teknologi Elektronika Perkeretaapian mengenai kegunaan mendeley dalam penulisan proposal penelitian tugas akhir. Kegiatan ini dilaksanakan di perpustakaan Politeknik Perkeretaapian Indonesia dengan peserta taruna-taruni Prodi D III Teknologi Elektronika Perkeretaapian. Metode yang digunakan dalam pelatihan ini berupa pembelajaran secara tatap muka dengan menggunakan laptop bagi masing-masing peserta. Hasil dari kegiatan ini taruna-taruni menjadi mampu untuk mencari referensi, memanajemen referensi, mensitasi dan membuat daftar pustaka menggunakan mendeley. Setelah pelaksanaan kegiatan taruna-taruni dapat membuat proposal tugas menggunakan mendeley.
\end{abstract}

Kata kunci-Aplikasi Mendeley, Taruna-Taruni, Tugas Akhir.

\begin{abstract}
This community service aims to improve the understanding and ability of cadets of the D III Railway Electronics Technology study program regarding the use of mendeley in writing a final project research proposal. This activity was carried out in the library of the Indonesian Railways Polytechnic with participants from the D III Railway Electronics Technology Study Program cadets. The method used in this training is face-to-face learning using a laptop for each participant. As a result of this activity, the cadets can find references, manage references, cite, and create a bibliography using Mendeley. After carrying out the activities, the cadets can make a task proposal using mendeley.
\end{abstract}

Keyword-Mendeley Application, Cadets-Taruni, Final Task.

\section{PENDAHULUAN}

Politeknik Perkeretaapian Indonesia Madiun merupakan sekolah vokasi yang berupa sekolah kedinasan di bawah Kementerian Perhubungan yang berada di kota Madiun. Di dalam Politeknik ini terdapat empat jurusan program studi antara lain D III Teknologi Jalur dan bangunan Perkeretaapian, D III Teknologi Elektronika Perkeretaapian, D III Teknologi Mekanika Perkeretaapian dan D III Manajemen Transportasi Perkeretaapian. Sejak tahun 2019 terdapat jalur regular pembibitan dan jalur regular non pembibitan. Taruna-taruni D III Teknologi Elektronika Perkeretaapian dan Prodi D III lainnya berada di asrama, namun semenjak adanya pandemic Covid-19 pembelajaran dilakukan secara online/daring. Pada tanggal 20 Oktober 2021 seluruh taruna-taruni tingkat tiga berada di kampus dan melakukan pembelajaran secara tatap muka.

Sesuai dengan tulisan dari Asean development Bank (ADB) dalam buku Reviews of National Policies for Education Education in Indonesia Rising to the Challengge maka di 
indonesia terdapat 5 jenis pendidikan vokasi yang terdiri dari : (1) Sekolah Menengah Kejuruan dan Madrasah Aliyah Kejuruan, (2) Akademi Komunitas; (3) Politeknik, (4) Universitas, dan (5) Balai Latihan Kerja (OECD \& Bank, 2015). Di dunia yang semakin menglobal ini persaingan menjadi semakin ketat di segala lini kehidupan, hal ini dikarenakan adanya perubahan dalam segala bidang, terutama teknologi. Agar tidak tertinggal dari negara lainnya maka Politeknik Perkeretaapian Indonesia perlu untuk mengupgrade diri. Terdapat 3 proses yang harus diketahui untuk menghadapi tantangan perubahan antara lain: (1) Unfreezing: yaitu proses adanya kesadaran untuk perlunya kebutuhan agar berubah; (2) Changing: langkah dalam bentuk tindakan baik untuk membuat lebih kuat driving force dan membuat lebih lemah resistence; (3) Refreezing: organisasi dibawa kembali pada keseimbangan yang baru (a new equilibrium).(Pratiwi et al., 2021)

Adanya pembelajaran tatap muka dianggap sebagai momentum yang tepat untuk memberikan pelatihan penggunaan mendeley dalam penulisan artikel untuk persiapan pembuatan proposal penelitian tugas akhir yang akan dibuat oleh taruna-taruni D III Teknologi Elektronika Perkeretaapian sebagai salah satu syarat kelulusan. Adapun hal-hal yang menguntungkan dalam pembelajaran tatap muka adalah sesuai dengan hasil pendataan yang mana hasilnya sebagian besar mahasiswa tidak untuk dating di perkuliahan dengan tatap muka dan dalam hal kehadiran di mata pelajaran pelajaran dengan tatap muka memberi pengaruh terhadap psikologis, emosional serta meneri bahan pembelajaran serta jalan keluar terhadap permasalahan pembelajaran. Dalam membuat laporan penelitian berupa makalah maupun laporan praktikum adalah pekerjaan rumah yang sering didapat oleh mahasiswa.

Penulisan ilmiah harus melihat beberapa unsur dari penggunaan bahasa baku, pilihan kata termasuk cara mensitasi dan pencatuman daftar pustaka secara tepat. Mensitasi dan menulis referensi ataupun daftar pustaka didalam penulisan ilmiah adalah hal yang tak terpisahkan karena penulisan ilmiah butuh referensi yang mampu membantu dalam meperkokoh sebuah pernyataan yang disampaikan penulis. Sumber kutipan harus dicantumkan dalam daftar pustaka.(Pinilih, 2021). Pada saat ini revolusi industri 4.0 memerlukan kurikulum yang dapat mewujudkan metode pembelajaran yang sesuai dengan dunia usaha dan dunia industri, seperti pembelajaran yang berlandaskan ilmu pengetahuan, memakais pembelajaran secara digital, pendekatan siswa sebagai pusatnya atau siswa yang harus aktif, model pembelajaran berdasarkan kerja sesuai era 4.0 yang berhubungan dengan bidang literasi data, literasi teknologi, dan literasi manusia sebagai sumber daya produktif dan profesional.(Verawadina et al., 2019).

Mendeley merupakan software manajemen referensi serta jaringan sosial akademis yang dapat melakukan menata publikasi hasil penelitian, menulis skripsi, thesis, desertasi, serta bekerjasama bersama peneliti lain dengan online dan memperoleh publikasi penelitian terakhir (Sayuti \& Puspasari, 2017). Banyak keuntungan dari pelatihan aplikasi mendeley yang diterima oleh mahasiswa antara lain mampu meningkatkan pengetahuan serta sebagai pendorong supaya mahasiswa lebih kreatif dalam menghasilkan referensi karya ilmiah yang menarik. Pelatihan yang diajarkan adalah sebuah kegiatan yang berfungsi membantu mahasiswa dalam memanajemen referensi dengan baik agar kualitas pendidikan di Indonesia dapat meningkat. Dalam pelaksanaannya mahasiswa cenderung masih banyak yang memakai cara konvensional dalam menulis karya ilmiah terutama di dalam mensitasi.(Perdana, 2020). Selain itu dalam membuat referensi yang diperoleh mahasiswa didalam daftar pustaka, mahasiswa juga punya masalah yaitu kesulitan dalam mengecek sitasi di daftar pustaka. Apabila di daftar pustaka ditemukan simbol yang terlewati atau tidak tertulis akan jadi sebuah kesalahan yang fatal. Apabila mahasiswa melaksanakan pengecekan di daftar pustaka masih menggunakan metode manual, hal ini akan memperlambat mahasiswa untuk menghasilkan sebuah laporan karya ilmiah.(Khanna Tiara, Untung Rahardja, 2016).

Dalam mendeley terdapat beberapa model gaya statement yang dapat diganti, seperti dari satu gaya ke gaya lainnya. Desain gaya referensi yang ditemukan dalam referensi Mendeley, antara lain American Medical Association, American Political Science Association, American Psychological Association, American Sociological Association, Chicago Manual of 
Style, Harvard, IEEE, Modern Humanities Research Association, Modern Language Association, National Library of Kedokteran, Alam, Vancouver, dan bermacam gaya lainnya. Penulis bisa mempunyai catatan referensi berupa softfile yang akurat serta menghindari kesalahan apabila di catat secara konvensial atau manual dengan cara memanfaatkan pengelolaan referensi.(Sungur \& Seyhan, 2013).

\section{METODE PELAKSANAAN}

Dalam pelaksanaan pengabdian masyarakat dengan peserta taruna-taruni D III Teknologi Elektronika Perkeretaapian yang terdiri dari kelas A yang merupakan kelas regular pembibitan terdapat sebanyak 24 orang taruna taruni, sedangkan kelas B yang merupakan kelas regular non pembibitan terdapat sebanyak 24 orang taruna-taruni. Pelaksanaan kegiatan pengabdian masyarakat ini dilakukan secara terpisah antara kelas A dan kelas B. dalam penelitian ini di bagi menjadi 3 tahapan yaitu

1. Tahap persiapan dimana dalam tahap ini di lakukan cek dan ricek apakah semua tarunataruni prodi D III Teknologi Elektronika Perkeretaapian kelas A dan kelas B sudah menginstal aplikasi mendeley di laptopnya masing-masing.

2. Tahap pelaksanaan yaitu pelaksanaan dari kegiatan pelatihan mendeley untuk taruna-taruni D III Teknologi perkeretaapian kelas A dan kelas B, dimana sebelum pelaksanaan kelas di bagikan googleform untuk diisi terlebih dahulu kemudian dilanjutkan dengan pemberian materi dan praktek secara tatap muka di perpustakaan Politeknik Perkeretaapian Indonesia.

3. Tahap evaluasi yaitu tahap dimana dilakukan evaluasi terhadap hasil pelatihan, pada tahap ini taruna kembali mengisi googleform terkait hasil yang diperoleh dari pelatihan mendeley tersebut untuk dapat dibandingkan dengan jawaban taruna taruni di googleform pada saat sebelum tahap pelaksanaan.

Dalam tahap setelah persiapan menuju tahap pelaksanaan maka taruna-taruni di berikan google form yang harus dijawab mengenai pengetahuan terkait aplikasi Mendeley yang terdiri dari:

1. Apakah taruna-taruni sudah menginstal, memahami dan menggunakan aplikasi mendeley dalam persiapan pembuatan proposal

2. Apakah taruna-taruni sudah menginstall dan cukup memahami dan cukup mampu menggunakan aplikasi mendeley dalam persiapan pembuatan proposal tugas akhir

3. Apakah taruna-taruni belum menginstal, belum memahami dan belum menggunakan aplikasi Mendeley dalam persiapan pembuatan proposal tugas akhir

Pada dasarnya bagian ini menjelaskan bagaimana pengabdian kepada masyarakat itu dilakukan. Materi pokok bagian ini adalah:

1. Sasaran pengabdian kepada masyarakat;

2. Tahapan pelaksanaan pengabdian masyarakat;

3. Proses pengabdian kepada masyarakat dan teknik analisis yang digunakan.

\section{HASIL DAN PEMBAHASAN}

Kegiatan dilaksanakan secara terpisah antara kelas A dan kelas B namun dengan materi yang sama. Adapun materi yang disajikan antara lain :

1. Tahap persiapan

a. Pada tahap persiapan ini dilakuakn cek dan ricek apakah taruna-taruni sudah melakukan Penginstalan aplikasi mendeley.

Taruna-taruni diajak untuk memasang aplikasi mendeley di laptopnya masing-masing. Didapatkan hasil bahwa hampir semua taruna-taruni sudah memasang aplikasi mendeley di laptopnya. Dari kelas A didapatkan hasil terdapat tiga orang taruna belum memasang aplikasi mendeley di laptopnya, sehingga pada saat tahap persiapan di download aplikasi mendeley dan 
di pasang di laptopnya masing-masing. Untuk taruna-taruni kelas B didapatkan hasil bahwa semua taruna taruni sudah memasang aplikasi mendeley dan tidak menemukan kendala.

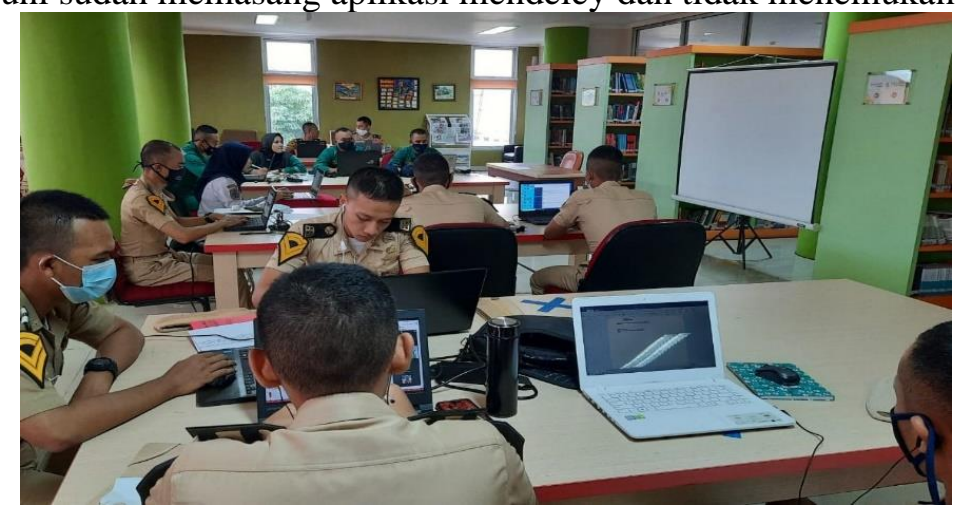

Gambar 1. Tahap Persiapan

b. Menghubungkan antara aplikasi mendeley dengan words.

Tahap berikutnya adalah menghubungkan aplikasi mendeley dengan words. Didapatkan hasil bahwa ada satu taruna yang mengalami kendala untuk menghubungkan aplikasi mendeley dengan words, sedangkan taruna-taruni di kelas B tidak mengalami kendala.

2. Tahap Pelaksanaan

a. Pada tahap pelaksanaan ini dilakuakn pengaplikasian mendeley untuk mensitasi artikel

Di tahap pengaplikasian mendeley untuk mensitasi artikel hampir semua taruna menyatakan belum bisa melakukan sitasi artikel. Maka pada tahap ini pemberian materi sangat bermanfaat bagi taruna-taruni. Materi pertama yang disampaikan adalah memasang aplikasi mendeley, kemudian menghubungkan mendeley dengan words dan selanjutnya adalah proses mensitasi artikel dengan menggunakan mendeley.

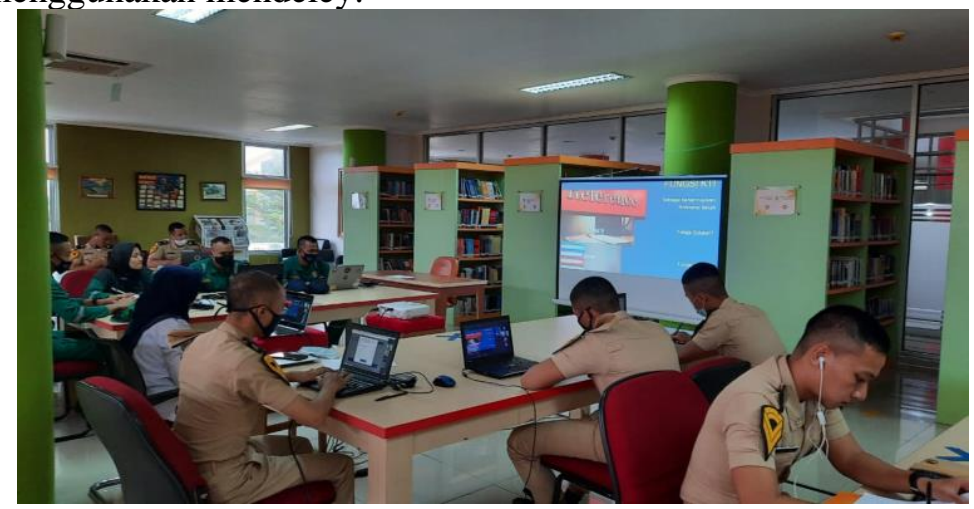

Gambar 2. Tahap Pelaksanaan Pelatihan Mendeley bagi taruna-Taruni D III Teknologi Elektronika Perkeretaapian di Perpustakaan

Taruna-taruni memperhatikan dengan seksama serta sangat antusias terhadap materi yang disampaikan dengan tidak segan untuk bertanya. Pada tahap ini diajarkan antara lain :

a. Membuat folder terlebih dahulu di mendeley agar file-file yang digunakan nantinya dapat tersimpan secara rapi dan menghemat waktu. Kemudian setelah disimpan dalam folder sendiri untuk file-file tersebut harus dilakukan cek dan ricek terlebih dahulu, apakah tipe filenya, judulnya, nama penulisnya, tahun terbitnya, halaman, abstrak, dll sudah sesuai ataukah belum. 


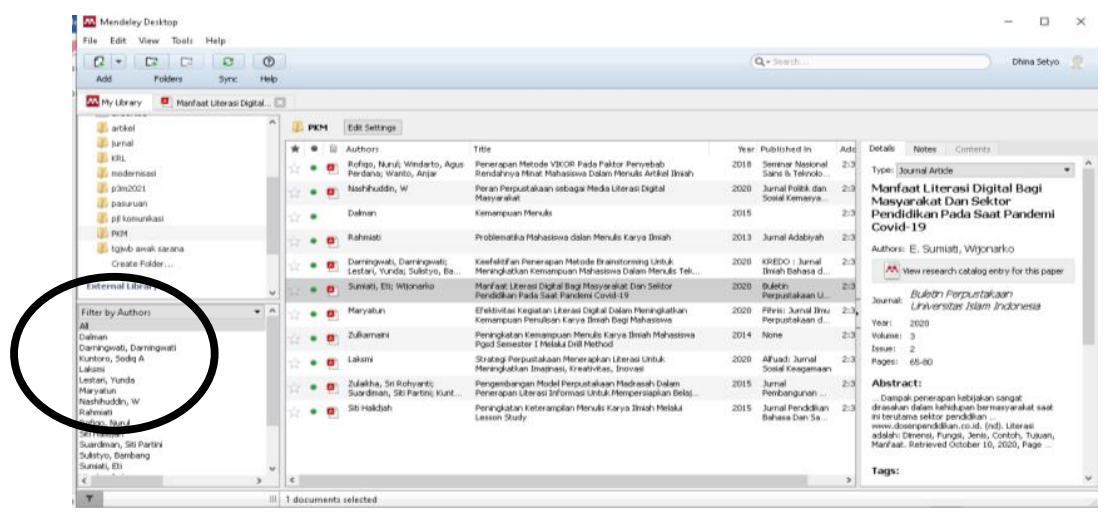

Gambar 3. Tampilan Membuat folder di Mendeley

b. Melakukan sitasi dengan cara di words pilih menu referensi kemudian pilih masukkan sitasi, setelah itu akan langsung terhubung secara otomatis dengan mendeley untuk kemudian disesuaikan untuk style pensitasiannya apakah menggunakan APA, IEEE, dll yang akan secara otomatis terhubung ke mendeley untuk kemudian pilih menu klik sitasi dan secara otomatis akan tersitasi.

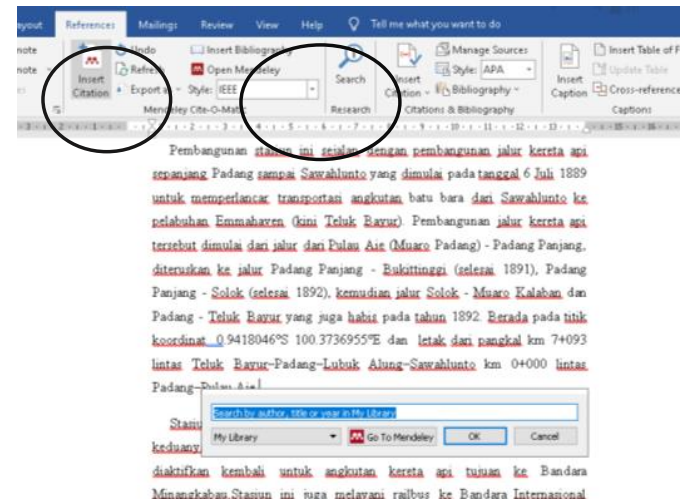

Gambar 4. Tampilan Sitasi Dengan Mendeley

c. Pemakaian mendeley untuk membuat daftar pustaka

Pada tahap ini apabila semua sitasi sudah selesaldilakukan maka tinggal selangkah lagi untuk membuat daftar pustaka. Di menu referensi tadi tinggal dimenekan tombol paste di halaman daftar pustaka kemudian memilih menu bibliography maka dengan sekali tekan daftar pustaka akan otomatis muncul sendiri di kolom daftar pustaka.

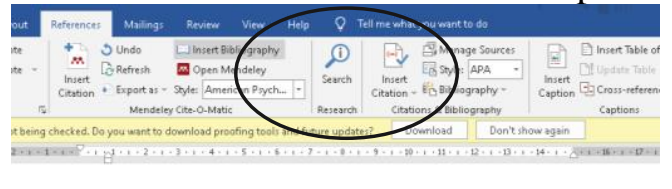

DAFTAR PUSTAKA

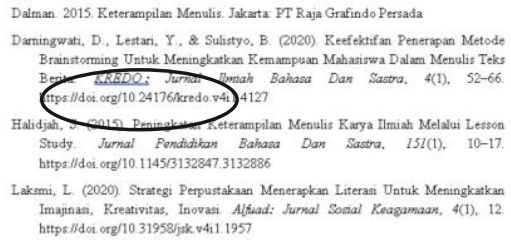

Gambar 5. Tampilan Daftar Pustaka Dengan Mendeley

3. Tahap evaluasi

Berdasarkan hasil google form yang diisi oleh taruna taruni pada saat sebelum dan sesudah pelaksanaan pelatihan mendeley didapatkan data sebagai berikut: 
Tabel 1. Hasil Jawaban Google Form Taruna-Taruni D III Teknologi Elektronika Perkeretaapian Pada Tahap Persiapan dan Tahap Evaluasi

D III TEP Kelas A

(Regular Pol;a Pembibitan)

Tahap Persiapan
3 taruna belum
menginstall aplikasi
mendeley

1 taruna mengalami

kesulitan

menghubungkan

mendeley dengan

words

18 orang taruna-taruni

belum mampu

mensitasi mendeley di

words

18 orang taruna-taruni

belum mampu

membuat folder di

mendeley

18 orang taruna-taruni

belum

membuat

pustaka mampu daftar otomatis

dengan mendeley
Tahap Evaluasi

24 orang taruna-

taruni

menginstall aplikasi mendeley

24 orang taruni dapat menghubungkan

dapat

mendeley words

24 orang taruna
taruni sudah mampu mensitasi mendeley ke words

24 orang tarunataruni mampu membuat folder di mendeley

24 orang taruni membuat pustaka dengan mendeley
D III TEP Kelas B

(Reguler Non pola Pembibitan)

Tahap Persiapan Tahap Evaluasi

24 orang taruna-taruni 24 orang tarunasudah menginstall taruni sudah aplikasi mendeley menginstall aplikasi mendeley

24 orang taruna-taruni dapat menghubungkan mendeley dengan words 24 orang tarunataruni dapat menghubungkan mendeley dengan words

20 orang taruna-taruni 24 orang taruna-
belum mampu taruni sudah mampu mensitasi mendeley di mensitasi mendeley words ke words

15 orang taruna-taruni 24 orang tarunabelum mampu taruni mampu membuat folder di membuat folder di mendeley mendeley

15 orang taruna-taruni 24 orang tarunabelum mampu taruni mampu membuat daftar membuat daftar pustaka otomatis pustaka otomatis dengan mendeley dengan mendeley

Berdasarkan Tabel 1 di atas maka didapatkan hasil bahwa terjadi perbedaan hasil yang cukup signifikan, dimana pada saat tahap persiapan masih terdapat beberapa taruna-taruni yang belum menginstal aplikasi mendeley ataupun ada yang mengalami kesulitan untuk menghubungkan mendeley dengan words. Pada prinsipnya sebagian besar taruna-taruni sudah menginstall aplikasi mendeley namun masih banyak yang belum tahu bagaimana menggunakan mendeley untuk memanajemen file-file yang akan dijadikan referensi data dukung persiapan pembuatan proposal penelitian untuk tugas akhir syarat kelulusan.

\begin{tabular}{|c|c|c|c|c|}
\hline \multirow{3}{*}{ Keterangan } & \multicolumn{2}{|c|}{ D III TEP Kelas A } & \multicolumn{2}{|c|}{ D III TEP Kelas B } \\
\hline & $\begin{array}{l}\text { (Regular } \\
\text { Pembibita }\end{array}$ & Pol;a & $\begin{array}{l}\text { (Reguler } \\
\text { Pembibita }\end{array}$ & Non pola \\
\hline & $\begin{array}{l}\text { Tahap } \\
\text { Persiapan }\end{array}$ & $\begin{array}{l}\text { Tahap } \\
\text { Evaluasi }\end{array}$ & $\begin{array}{l}\text { Tahap } \\
\text { Persiapan }\end{array}$ & $\begin{array}{l}\text { Tahap } \\
\text { Evaluasi }\end{array}$ \\
\hline Mampu menginstall aplikasi mendeley & $87 \%$ & $100 \%$ & $100 \%$ & $100 \%$ \\
\hline $\begin{array}{l}\text { Mampu menghubungkan Mendeley dengan } \\
\text { words }\end{array}$ & $96 \%$ & $100 \%$ & $100 \%$ & $100 \%$ \\
\hline Mampu mensitasi mendeley di words & $25 \%$ & $100 \%$ & $17 \%$ & $100 \%$ \\
\hline Mampu membuat folder di mendeley & $25 \%$ & $100 \%$ & $37 \%$ & $100 \%$ \\
\hline $\begin{array}{l}\text { Mampu membuat daftar Pustaka otomatis } \\
\text { dengan Mendeley }\end{array}$ & $25 \%$ & $100 \%$ & $37 \%$ & $100 \%$ \\
\hline
\end{tabular}


Berdasarkan Tabel 2 di atas luaran hasil pelatihan aplikasi mendeley untuk taruna-taruni D III Politeknik Perkeretaapian Indonesia adalah 100\% dapat menginstall aplikasi mendeley, kemudian mampu menghubungkan mendeley dengan words, sehingga mampu mensitasi file referensi dan dapat membuat folder di mendeley untuk menyimpan file. serta mampu untuk membuat daftar pustaka. Dengan adanya pelatihan mendeley yang dilaksanakan selama satu hari dengan durasi waktu 180 menit atau 3 jam pada tanggal 25 Oktober 2021 pukul 15.00 sampai dengan selesai untuk kelas A dan tanggal 26 Oktober 2021 pukul 15.00 sampai dengan selesai untuk kelas B dengan hasil mampu mengaplikasikan mendeley.

\section{KESIMPULAN}

Pelatihan Mendeley untuk taruna-taruni D III Teknologi Elektronika Perkeretaapian sangat bermanfaat untuk persiapan pembuatan proposal penelitian tugas akhir taruna-taruni yang akan dilaksanakan pada saat nanti duduk di semester enam. Taruna-taruni dapat mempersiapkan diri lebih awal untuk memulai menulis penelitian dengan keluaran berupa proposal penelitian tugas akhir. Dengan Mendeley dapat menghemat waktu dan menyimpan file dengan aman bila dibandingkan dengan cara manual. Selain itu juga memudahkan dosen penguji dan dosen pembimbing untuk menemukan file-file referensi yang digunakan oleh taruna-taruni tersebut. Pada saat semester enam yang akan dilaksanakan di bulan Februari 2022 taruna-taruni sudah ada bekal dalam penggunaan aplikasi mendeley.

\section{DAFTAR PUSTAKA}

Khanna Tiara, Untung Rahardja, I. A. R. (2016). Pemanfaatan Google Scholar Dan Citation Dalam Memenuhi Kebutuhan Pembuatan Skripsi Mahasiswa Pada Perguruan Tinggi. Technomedia Journal (TMJ), 1(1), 95-113.

OECD, \& Bank, A. D. (2015). Reviews of National Policies for Education in Indonesia: Rising To The Challenge. In Corrigenda. Corrigenda. https://doi.org/http://dx.doi.org/10.1787/9789264230750-en ISBN.

Perdana, F. J. (2020). Pelatihan Membuat Daftar Pustaka Otomatis Dengan Aplikasi Mendeley Desktop Bagi Mahasiswa Dalam Persiapan Penyusunan Tugas Akhir. Dimasejati: Jurnal Pengabdian Kepada Masyarakat, 2(1), 75. https://doi.org/10.24235/dimasejati.v2i1.6652.

Pinilih, M. (2021). Pelatihan Penggunaan mendeley Bagi Mahasiswa Guna Mengelola Referensi Ilmiah. Dinamika Journal, 3(1), 17-23.

Pratiwi, D. I., Astuti, S. W., Puspitasari, A., \& Fikria, A. (2021). Analisis Tata Kelola Perguruan Tinggi Vokasi dan Indeks Kepuasan Siswa pada Politeknik Perkeretaapian Indonesia Madiun. Edukatif : Jurnal Ilmu Pendidikan, 3(6), 45564567.

Sayuti, M., \& Puspasari, C. (2017). Menguasai Mendeley; Manajemen Pengutipan Referensi untuk Karya Ilmiah. In Universitas Malikussaleh. Universitas Malikussaleh.

Sungur, M. O., \& Seyhan, T. Ö. (2013). Writing References and Using Citation Management Software. Turkish Journal of Urology, 39(SUPPL. 1), 25-32. https://doi.org/10.5152/tud.2013.050.

Verawadina, U., Jalinus, N., \& Asnur, L. (2019). Mengkaji Kurikulum Di Era Revolusi Industri 4.0 Bagi Pendidikan Vokasi. Wahana Didaktika: Jurnal Ilmu Kependidikan, $17(2)$, $17(2)$, 228-239. https://doi.org/10.31851/wahanadidaktika.v17i2.2834. 